\title{
Targeted Next-Generation Sequencing of Plasma Cell- Free DNA in Korean Patients with Hepatocellular Carcinoma
}

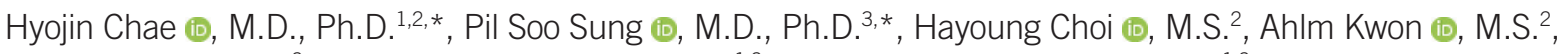 \\ Dain Kang (ㅁ), B.S.E. ${ }^{2}$, Yonggoo Kim (1), M.D., Ph.D. ${ }^{1,2}$, Myungshin Kim (D), M.D., Ph.D. ${ }^{1,2, *}$, \\ and Seung Kew Yoon 미, M.D., Ph.D., ${ }^{3, *}$ \\ ${ }^{1}$ Department of Laboratory Medicine, College of Medicine, The Catholic University of Korea, Seoul, Korea; ${ }^{2}$ Catholic Genetic Laboratory Center, Seoul St. \\ Mary's Hospital, College of Medicine, The Catholic University of Korea, Seoul, Korea; ${ }^{3}$ Department of Internal Medicine, Seoul St. Mary's Hospital, The \\ Catholic University Liver Research Center, College of Medicine, The Catholic University of Korea, Seoul, Korea
}

Background: Hepatocellular carcinoma (HCC) is the second-most-common cause of cancer-related deaths worldwide, and an accurate and non-invasive biomarker for the early detection and monitoring of HCC is required. We assessed pathogenic variants of HCC driver genes in cell-free DNA (cfDNA) from HCC patients who had not undergone systemic therapy.

Methods: Plasma cfDNA was collected from $20 \mathrm{HCC}$ patients, and deep sequencing was performed using a customized cfDNA next-generation sequencing panel, targeting the major HCC driver genes (TP53, CTNNB1, TERT) that incorporates molecular barcoding.

Results: In 13/20 (65\%) patients, we identified at least one pathogenic variant of two major HCC driver genes (TP53 and CTNNB1), including 16 variants of TP53 and nine variants of CTNNB1. The TP53 and CTNNB1 variants showed low allele frequencies, with median values of $0.17 \%$ (range: $0.06 \%-6.99 \%$ ) and $0.07 \%$ (range: $0.05 \%-0.96 \%$ ), respectively. However, the molecular coverage of variants was sufficient, with median values of 5,543 (range: 2,317-9,088) and 7,568 (range: 2,400-9,633) for TP53 and CTNNB1 variants, respectively.

Conclusions: Our targeted DNA sequencing successfully identified low-frequency pathogenic variants in the cfDNA from HCC patients by achieving high coverage of unique molecular families. Our results support the utility of cfDNA analysis to identify somatic gene variants in $\mathrm{HCC}$ patients.

Key Words: Hepatocellular carcinoma, Cell-free DNA, Next-generation sequencing, Molecular barcoding, Pathogenic variants, TP53, CTNNB1, TERT
Received: February 2, 2020

Revision received: May 17, 2020

Accepted: September 19, 2020

\section{Corresponding author:}

Myungshin Kim, M.D., Ph.D., Department of Laboratory Medicine Seoul St. Mary's Hospital, College of Medicine, The Catholic University of Korea, 222 Banpo-daero, Seocho-gu, Seoul

06591, Korea

Tel: +82-2-2258-1645

Fax: +82-2-2258-1719

E-mail: microkim@catholic.ac.kr

\section{Co-corresponding author:}

Seung Kew Yoon, M.D., Ph.D.,

Division of Hepatology, Department of Internal Medicine, College of Medicine, The Catholic University of Korea, 222 Banpodaero, Seocho-gu, Seoul 06591, Korea

Tel: +82-2-2258-2073

Fax: +82-2-3481-4025

E-mail: yoonsk@catholic.ac.kr

*These authors contributed equally to this work.

\section{(i) ()}

(c) Korean Society for Laboratory Medicine This is an Open Access article distributed under the terms of the Creative Commons Attribution Non-Commercial License (https://creativecommons.org/licenses/by-nc/4.0) which permits unrestricted non-commercial use, distribution, and reproduction in any medium, provided the original work is properly cited.

\section{INTRODUCTION}

Hepatocellular carcinoma (HCC) is the second-most-common cause of cancer-related deaths worldwide [1]. In Korea, the mortality rate of HCC was 21.5 per 100,000 population in 2016, and HCC ranked as the second-leading cause of cancer-related deaths [2]. The major risk factors of HCC include chronic hepatitis $B$ virus (HBV) and hepatitis $C$ virus infection, alcohol abuse, 
liver cirrhosis, and exposure to aflatoxin B1 [3]. Alpha-fetoprotein (AFP) is the most widely used biomarker for early detection of HCC. However, AFP has poor reliability and low sensitivity for early-stage HCC detection [4]. The lack of an early diagnostic marker for HCC has posed a major challenge to curative treatments, including liver resection and liver transplantation. In addition, early detection of recurrence during monitoring after curative therapy is associated with improved survival in HCC patients [5]. Thus, for early detection of HCC as well as for recurrence monitoring after curative surgical resection, an accurate and non-invasive HCC biomarker is required [6].

Circulating cell-free DNA (cfDNA) has potential as a noninvasive biomarker for detecting and monitoring tumor cells. In addition, cfDNA has prognostic value and may be useful in strategies to select patients eligible for targeted therapy [7, 8]. Several studies have demonstrated significantly higher cfDNA levels in sera and plasma of patients with both early and advanced HCC $[9,10]$. Recent studies have explored HCC-related genomic alterations and have identified frequent gene variants, including those in the TERT promoter, TP53, and CTNNB1 (beta-catenin), in both early and advanced HCC samples [11, 12]. However, the analysis of cfDNA is challenging because of its short half-life and low concentration in the plasma; it is even more challenging to detect tumor-derived cfDNA, which accounts for a very small fraction of the total cfDNA [13]. Therefore, various methods have been applied for cfDNA analysis, including quantitative PCR, digital PCR, BEAMing, and next-generation sequencing (NGS) [14]. While all these methods enable sensitive detection of target genes, only NGS facilitates the parallel detection of a broad range of variants of multiple gene targets [15]. This is especially important for HCC, as most somatic variants in HCC are not located in hotspots, and this is relevant even for variants in HCC driver genes [16, 17].

In this study, we aimed to assess pathogenic variants of HCC driver genes in cfDNA from advanced HCC patients who had not undergone systemic therapy. We used a customized targeted NGS panel that incorporates unique molecular identifiers (UMIS) to reduce PCR-based NGS errors and to distinguish reads amplified from the same original DNA molecule (on the basis of identical UMIs).

\section{MATERIALS AND METHODS}

\section{Participants}

Twenty patients, including 17 men and 3 women with a median age of 60 years (range: 47-79 years), admitted at Seoul St. Mary's
Hospital, Seoul, Korea, between June 2018 and May 2019 were enrolled in this study. All patients were diagnosed as having HCC according to the guidelines from the American Association for the Study of Liver Diseases and the European Association for the Study of the Liver [18]. Cirrhosis was present in all 20 (100\%) patients, with viral hepatitis $\mathrm{B}$ being the main etiology for the underlying liver disease in 15/20 (75\%) patients. Most patients had multiple nodules (17/20, 85\%), and macrovascular invasion and metastasis were present in 9/20 (45\%) and 14/20 (70\%) patients, respectively (Table 1). All participants, including three healthy adults recruited as healthy controls, provided written informed consent. This study was conducted in accordance with the Declaration of Helsinki and was approved by the Institutional Review Board/Ethics Committee of Seoul St. Mary's Hospital (IRB No. K18TESI0295).

\section{Sample collection and cfDNA extraction}

Peripheral blood samples $(10 \mathrm{~mL})$ were drawn in ethylenediaminetetraacetic acid (EDTA)-containing tubes, and plasma was separated within one $\mathrm{hr}$ of collection in two centrifugation steps: $2,000 \times \mathrm{g}$ at $4^{\circ} \mathrm{C}$ for 10 minutes, followed by $16,000 \times \mathrm{g}$ at $4^{\circ} \mathrm{C}$ for 10 minutes [19]. Plasma samples were immediately aliquoted and stored at $-80^{\circ} \mathrm{C}$ for up to nine months.

Circulating cfDNA was isolated from $4 \mathrm{~mL}$ of plasma using the MagMAX Cell-Free DNA Isolation Kit (Applied Biosystems, Waltham, MA, USA) and the KingFisher Duo Prime Magnetic Particle Processor (Thermo Fisher Scientific, Waltham, MA, USA), according to the manufacturer's instructions. The size of the purified plasma DNA was estimated using a 2,100 Bioanalyzer System (Agilent Technologies, Santa Clara, CA, USA), and its concentration was determined using a Qubit fluorometer (Thermo Fisher Scientific) in combination with a Qubit dsDNA HS Assay Kit (Thermo Fisher Scientific), according to the manufacturer's instructions. Seraseq ctDNA Reference Material v.2 (SeraCare Life Sciences, Milford, MA, USA) was used to validate the limit of detection. The reference material consisted of 40 cancer-relevant somatic variants spiked into a background of wild-type DNA (purified from a reference cell line, GM24385) at defined variant allele frequencies (VAFs) of $2 \%, 1 \%, 0.5 \%$, $0.25 \%, 0.125 \%$, and $0 \%$ [20]. Seraseq ctDNA was extracted and analyzed in duplicate. Methods used for library preparation and sequencing were the same as those used for the participant samples.

\section{Targeted NGS}

We designed a custom 88-amplicon panel (mean read length: 
Table 1. Demographics and clinical characteristics of the patients

\begin{tabular}{|c|c|c|}
\hline Variable & & Patients (N) \\
\hline Age (yr) & Median (range) & $60(47-79)$ \\
\hline \multirow[t]{2}{*}{ Gender } & Female & 3 \\
\hline & Male & 17 \\
\hline \multirow[t]{4}{*}{ BCLC classification } & $A$ & 0 \\
\hline & $B$ & 2 \\
\hline & C & 18 \\
\hline & $\mathrm{D}$ & 0 \\
\hline \multirow[t]{2}{*}{ Cirrhosis } & Yes & 20 \\
\hline & No & 0 \\
\hline \multirow[t]{4}{*}{ Tumor size (cm) } & $<3$ & 3 \\
\hline & $3-5$ & 2 \\
\hline & $5-10$ & 5 \\
\hline & $\geq 10$ & 10 \\
\hline \multirow[t]{2}{*}{ Macrovascular invasion } & Absent & 11 \\
\hline & Present & 9 \\
\hline \multirow[t]{5}{*}{$\operatorname{AFP}(\mu g / L)$} & $<20$ & 3 \\
\hline & $20-100$ & 3 \\
\hline & $100-400$ & 1 \\
\hline & $400-1,000$ & 1 \\
\hline & $\geq 1,000$ & 12 \\
\hline \multirow[t]{2}{*}{ Multiplicity } & Absent & 3 \\
\hline & Present & 17 \\
\hline \multirow[t]{2}{*}{ Metastasis } & Absent & 6 \\
\hline & Present & 14 \\
\hline \multirow[t]{2}{*}{ HBV } & Absent & 5 \\
\hline & Present & 15 \\
\hline \multirow[t]{2}{*}{ HCV } & Absent & 17 \\
\hline & Present & 3 \\
\hline \multirow[t]{2}{*}{ ALD } & Absent & 17 \\
\hline & Present & 3 \\
\hline
\end{tabular}

Abbreviations: BCLC, Barcelona clinic liver cancer staging; AFP, alpha-fetoprotein; HBV, hepatitis B virus; HCV, hepatitis C virus; ALD, alcoholic liver disease.

$107 \mathrm{bp}$ ) targeting three HCC driver genes, namely TP53, CTNNB1, and TERT, using the Ion AmpliSeq Designer (Thermo Fisher Scientific) and the "white glove" design option, a program that facilitates additional customization to design amplicons for difficult regions. Two primer pools were designed to interrogate the entire coding regions of TP53 and CTNNB1, including $5 \mathrm{bp}$ of the $5^{\prime}$ and $3^{\prime}$ intronic sequences of each exon, and TERT promoter variants (primer sequences can be provided on request). The target design rate was 100\% for TP53,
CTNNB1, and for TERT, totaling $3.92 \mathrm{~kb}$. The lon AmpliSeq HD panel enabled molecular tagging of each DNA input molecule using UMIs.

We used the optimal amount of input cfDNA (20 ng in $8.3 \mu \mathrm{L}$ ) recommended by the manufacturer to generate libraries using an Ion AmpliSeq HD library kit (Thermo Fisher Scientific) and the Custom Ion AmpliSeq HD panel. Library quantification was performed using the TapeStation 2200 High Sensitivity D1000 Kit (Agilent Technologies). Clonal amplification of the libraries was performed by emulsion PCR on an lon Chef System using an Ion 540 Kit-Chef (Thermo Fisher Scientific). Template-positive ion sphere particles were enriched, loaded on an lon 540 Chip, and sequenced using an Ion S5 XL Sequencer (Thermo Fisher Scientific), according to the manufacturer's instructions.

Sequence data were processed for primary and secondary analyses, using standard Ion Torrent Suite Software (Thermo Fisher Scientific) running on the Torrent Server (Thermo Fisher Scientific). Raw signal data were analyzed using Torrent Suite v. 5.10.1 (Thermo Fisher Scientific) and Ion Reporter (Thermo Fisher Scientific). The pipeline included signal processing, base calling, quality score assignment, adapter trimming, PCR duplicate removal, read alignment, mapping quality control, coverage analysis, and variant calling. The sequenced reads were aligned against the hg19 reference genome (Genome Reference Consortium GRCh37). Sequence variants were identified using the Ion Reporter software v. 5.10 (Thermo Fisher Scientific) and Ion AmpliSeq HD Workflow template for Liquid Biopsy-w2.1-DNA-Single Sample, and the coverage of each amplicon was determined using the Coverage Analysis Plugin Software v. 5.10.0 (Thermo Fisher Scientific). The application of UMIs enabled the grouping of reads into molecular families. Random errors generated during library construction and the sequencing process were removed automatically. At least three independent molecular families were required to identify and call a variant.

\section{Statistical analysis}

Categorical clinical variables between patients with and without pathogenic or likely pathogenic variants identified in the cfDNA were compared using Fisher's exact test. Observed and designed VAFs were compared using Spearman's rank correlation and Passing-Bablok regression. Statistical analyses were performed using MedCalc v. 17.2 (MedCalc Software, Ostend, Belgium). $P<0.05$ was considered statistically significant. 


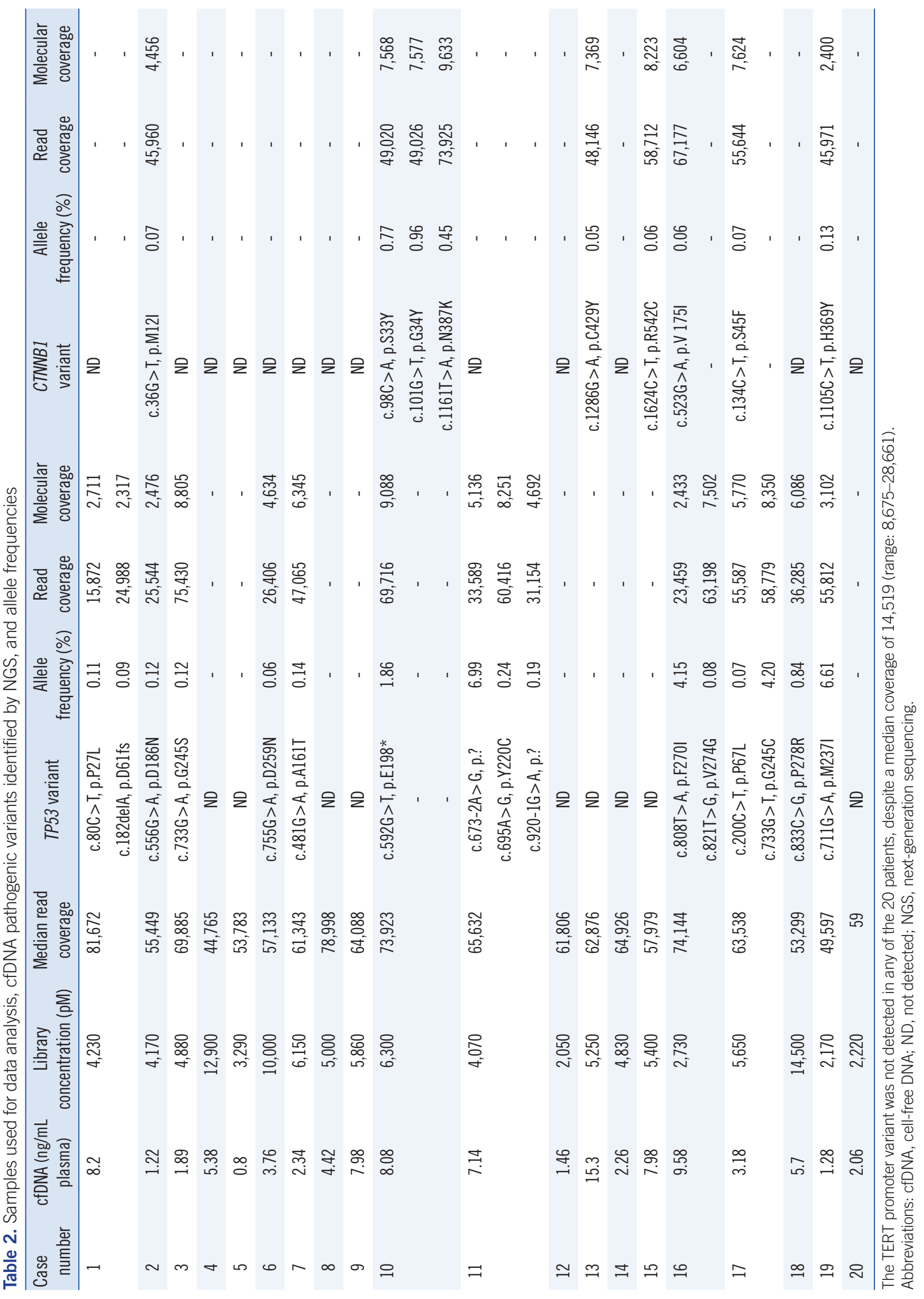



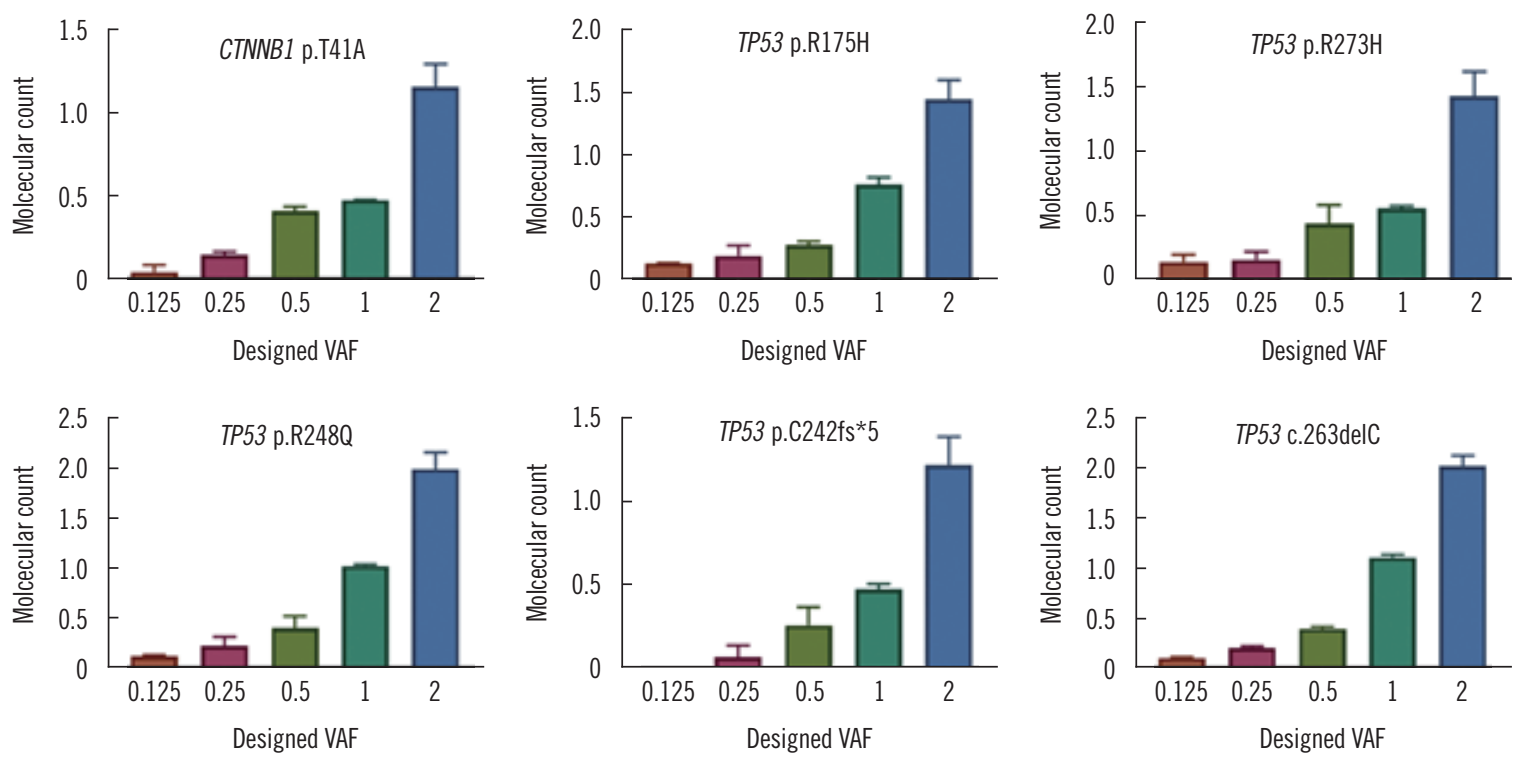

Fig. 1. Mean observed molecular count (VAF) compared with the designed VAF of the reference material for the six variants. Abbreviation: VAF, variant allele frequency.

\section{RESULTS}

cfDNA amount and summary of the sequencing metrics The cfDNA output of each sample and the sequencing metrics are presented in Table 2. The median concentration of plasma cfDNA from all HCC patients was $4.1 \mathrm{ng} / \mathrm{mL}$ (range: 0.8-15.3 $\mathrm{ng} / \mathrm{mL}$ ). The library concentrations were $2,050-14,500 \mathrm{pM}$. The median sequencing coverage was 62,694 (range: 44,76581,672 ), and all 20 samples had a median read coverage greater than 25,000 , which is the median read coverage across targets specified by the manufacturer to ensure a $0.1 \%$ limit of detection.

Validation of the limit of detection using reference material The results of the analysis of the reference materials for six variants (one in CTNNB1 and five in TP53) included in our custom panel design are shown in Fig. 1. Of the six variants, only TP53 p.C242fs $* 5$ was detected at $0.25 \%$; all other variants were detected at $0.125 \%$. The Spearman's rank correlation coefficient for each variant ranged from 0.95 to 0.99 , indicating a strong correlation between the observed and designed VAFs. PassingBablok regression results for comparisons of the observed and designed VAFs for each of the six variants are shown Fig 2. The slope of the linear regression line for each variant ranged from 0.57 to 1.03 , and for the TP53 p.R248Q and TP53 p.C242fs*5 variants, the $95 \%$ confidence interval of the slope contained 1.0.
Low-frequency variant detection in three HCC driver genes Targeted NGS using an in-house panel of three HCC driver genes identified at least one pathogenic variant in the plasma cfDNA of 13/20 patients (65\%). These included 16 variants of TP53 and nine variants of CTNNB1. The TP53 and CTNNB1 variants had low-level allele frequencies with median values of $0.17 \%$ (range: $0.06 \%-6.99 \%$ ) and $0.07 \%$ (range: $0.05 \%-$ $0.96 \%$ ), respectively. However, the molecular coverages of the TP53 and CTNNB1 variants detected in cfDNA were sufficient, with median values of 5,543 (range: 2,317-9,088) and 7,568 (range: 2,400-9,633), respectively. Of note, no pathogenic variants were identified in the three healthy control samples.

Of the 16 pathogenic variants of TP53, 12 (75\%) were missense, $13(81 \%)$ were located in the DNA-binding domain in exons 4-8 of TP53, and two (13\%) were located at codon 245, which is one of the major hotspots of somatic TP53 pathogenic variants. Of the nine variants of CTNNB1, four were located at known hotspots [18-21], two (S33Y, G34Y) were located within the $\beta$ - $\operatorname{TrCP}$ binding domain (D32-S37), one (S45F) involved S45, an amino acid residue involved in the phosphorylation/ degradation of $\beta$-catenin, and one was located in the armadillo repeat six domain (N387). Probably due to the small number of patients included in this study, we did not find a statistically significant association between clinical characteristics and the presence of TP53 and/or CTNNB1 cfDNA variants (Table 3). 


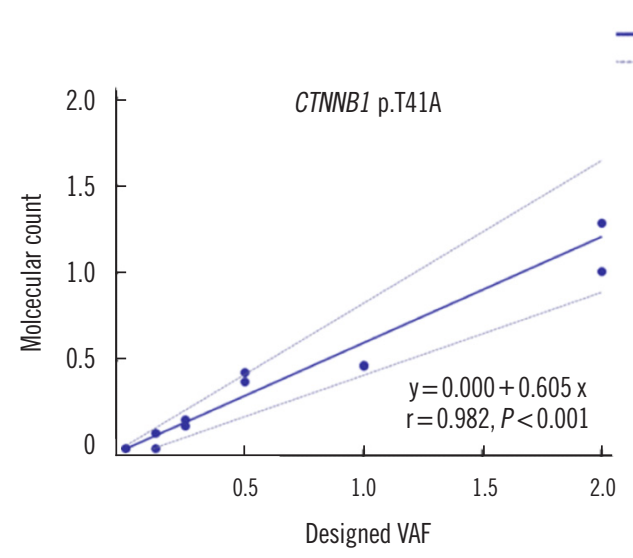

Regression

$95 \% \mathrm{Cl}$
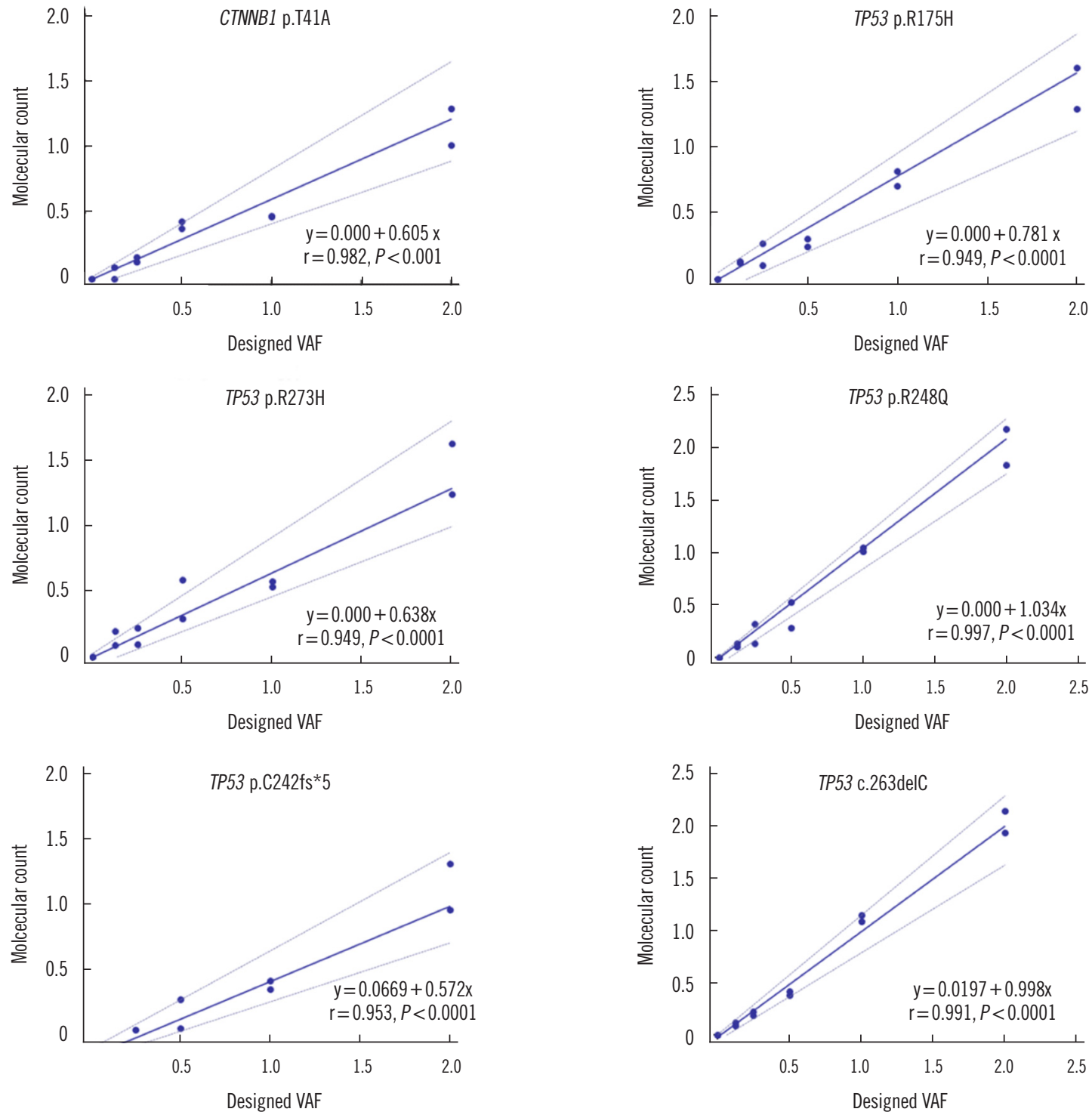

Fig. 2. Passing-Bablok regression analysis plots for comparison of the observed and designed VAFs for each of the six variants are shown. The slope of the linear regression line for each variant ranged from 0.57 to 1.03, and, for TP53 p.R248Q and TP53 p.C242fs*5 variants, the $95 \%$ confidence interval $(\mathrm{Cl})$ of the slope contained 1.0 .

Abbreviation: VAF, variant allele frequency.

\section{DISCUSSION}

In the present study, we identified 16 pathogenic variants of TP53 and nine pathogenic variants of CTNNB1 from the cfDNA of patients with advanced HCC. In both TP53 and CTNNB1, relations between somatic variants and prognosis in HCC were identified [7, 21]. The presence of TP53 pathogenic variants in HCC was significantly associated with shorter survival and disease-free survival, and the R249C variant, one of the most com- mon TP53 pathogenic variants in HCC, was a better indicator for poor prognosis than the TP53 pathogenic and likely pathogenic variants combined [7]. Recent HCC variant screening studies have shown significant progress at identifying potentially targetable pathogenic variants $[8,22]$. Therefore, in addition to early detection and monitoring of HCC, cfDNA can be useful for prognostication and in strategies to select patients eligible for targeted therapy.

Two recent studies investigated the molecular landscape of 
Table 3. Correlations between clinical characteristics and HCC driver gene pathogenic variants detected in cfDNA

\begin{tabular}{|c|c|c|c|c|c|c|c|c|c|c|}
\hline & & $\begin{array}{l}\text { Patients with } \\
\text { variants in } \\
\text { cfDNA (\%) }\end{array}$ & $\begin{array}{c}\text { Patients } \\
\text { without } \\
\text { variants in } \\
\text { cfDNA (\%) }\end{array}$ & $P$ & $\begin{array}{l}\text { Patients with } \\
\text { TP53 variants } \\
\text { in cfDNA (\%) }\end{array}$ & $\begin{array}{c}\text { Patients } \\
\text { without TP53 } \\
\text { variants in } \\
\text { cfDNA (\%) }\end{array}$ & $P$ & $\begin{array}{c}\text { Patients with } \\
\text { CTNNB1 } \\
\text { variants in } \\
\text { cfDNA (\%) }\end{array}$ & $\begin{array}{c}\text { Patients } \\
\text { without } \\
\text { CTNNB1 } \\
\text { variants in } \\
\text { cfDNA (\%) }\end{array}$ & $P$ \\
\hline \multirow[t]{2}{*}{ Sex } & Male $(\mathrm{N}=17)$ & 65 & 35 & 1.00 & 53 & 47 & 1.00 & 29 & 71 & 0.27 \\
\hline & Female $(\mathrm{N}=3)$ & 67 & 33 & & 67 & 33 & & 67 & 33 & \\
\hline \multirow[t]{2}{*}{ Macrovascular invasion } & Yes $(N=9)$ & 56 & 44 & 0.64 & 44 & 6 & 0.65 & 33 & 67 & 1.00 \\
\hline & № $(\mathrm{N}=11)$ & 73 & 27 & & 64 & 36 & & 36 & 64 & \\
\hline \multirow[t]{2}{*}{ Multiplicity } & Yes $(N=17)$ & 59 & 41 & 0.52 & 47 & 53 & 0.22 & 29 & 71 & 0.27 \\
\hline & $\mathrm{N}_{0}(\mathrm{~N}=3)$ & 100 & 0 & & 100 & 0 & & 67 & 33 & \\
\hline \multirow[t]{2}{*}{ Metastasis } & Yes $(N=14)$ & 64 & 36 & 1.00 & 50 & 50 & 0.64 & 36 & 64 & 1.00 \\
\hline & № $(\mathrm{N}=6)$ & 67 & 33 & & 67 & 33 & & 33 & 67 & \\
\hline \multirow[t]{2}{*}{ HBV } & Positive (N=15) & 67 & 33 & 1.00 & 53 & 47 & 1.00 & 33 & 67 & 1.00 \\
\hline & Negative (N=5) & 60 & 40 & & 60 & 40 & & 40 & 60 & \\
\hline \multirow[t]{2}{*}{ HCV } & Positive (N=3) & 33 & 67 & 0.27 & 33 & 67 & 0.57 & 33 & 67 & 1.00 \\
\hline & Negative $(\mathrm{N}=17)$ & 71 & 29 & & 59 & 41 & & 35 & 65 & \\
\hline \multirow[t]{2}{*}{ ALD } & Yes $(N=3)$ & 67 & 33 & 1.00 & 67 & 33 & 1.00 & 33 & 67 & 1.00 \\
\hline & № $(N=17)$ & 65 & 35 & & 53 & 47 & & 35 & 65 & \\
\hline
\end{tabular}

Abbreviations: cfDNA, cell-free DNA; HBV, hepatitis B virus; HCC, hepatocellular carcinoma; HCV, hepatitis C virus; ALD, alcoholic liver disease.

Table 4. Comparison of published studies on cfDNA in HCC patients using targeted sequencing

\begin{tabular}{|c|c|c|c|c|c|c|c|c|}
\hline Reference & Stage of HCC & Sample & Genes & $\begin{array}{l}\text { Median coverage } \\
\text { (range) }\end{array}$ & $\begin{array}{l}\text { Claimed } \\
\text { analytical } \\
\text { sensitivity }\end{array}$ & $\begin{array}{l}\text { Most common } \\
\text { altered gene }\end{array}$ & $\begin{array}{c}\text { Detection of } \geq 1 \\
\text { somatic variants in } \\
\text { cfDNA (\%) }\end{array}$ & $\begin{array}{l}\text { Median variant allele } \\
\text { frequency (\%) }\end{array}$ \\
\hline \multirow[t]{2}{*}{$\begin{array}{l}\text { Howell, et al., } \\
2019 \text { [23] }\end{array}$} & $\begin{array}{c}\text { early (39\%) and } \\
\text { advanced (61\%) HCC }\end{array}$ & $N=51$ & 8 & $\begin{array}{c}486 x \\
\text { (IQR: } 234 x-797 x)\end{array}$ & NA & ARID1A & 35 & $\begin{array}{c}11.9 \\
\text { (IQR: } 5-42.3)\end{array}$ \\
\hline & & $\begin{array}{l}\text { (8 with paired } \\
\text { tumor biopsy) }\end{array}$ & & & & & & \\
\hline $\begin{array}{l}\text { Kaseb, et al., } \\
2019 \text { [22] }\end{array}$ & advanced HCC & $N=206$ & $54-70$ & NA & $0.1 \%$ LoD & TP53 & $\begin{array}{l}\text { NA (detection of } \geq 1 \\
\text { alterations in } \\
\text { cfDNA: 87.8) }\end{array}$ & $\begin{array}{c}0.49 \\
\text { (range, } 0.06-55.03 \text { ) }\end{array}$ \\
\hline \multirow[t]{2}{*}{$\begin{array}{l}\text { Ng, et al., } \\
2018 \text { [25] }\end{array}$} & $\begin{array}{c}\text { early (67\%) and } \\
\text { advanced (33\%) HCC }\end{array}$ & $N=30$ & 46 & $\begin{array}{c}1,239 x \\
(703 x-3,244 x)\end{array}$ & $0.1 \%$ LoD & TP53 & 63 & $\begin{array}{c}13.7 \\
\text { (range, } 0.06-44.9 \text { ) }\end{array}$ \\
\hline & & $\begin{array}{l}\text { (with paired } \\
\text { tumor biopsy) }\end{array}$ & & & & & & \\
\hline Present study & advanced HCC & $N=20$ & 3 & $\begin{array}{c}63,482 x \\
(44,765 x-81,672 x)\end{array}$ & $0.1 \%$ LoD & TP53 & 65 & $\begin{array}{c}0.13 \\
\text { (range, } 0.06-6.99 \text { ) }\end{array}$ \\
\hline
\end{tabular}

Abbreviations: cfDNA, cell-free DNA; HCC, hepatocellular carcinoma; NA, not available; LoD, limit of detection; IQR, interquartile range.

cfDNA in HCC patients [22, 23] (Table 4). In the European study, 29 pathogenic or likely pathogenic variants in eight genes were detected in 18/51 (35\%) patients. The median read depth was 486, and the median VAF was 0.12. In the study on 206 HCC patients from the USA, alterations, including amplifications, synonymous alterations, and variants of undetermined significance, in addition to pathogenic or likely pathogenic variants, were detected in 181/206 (87.8\%) patients. The median VAF was $0.49 \%$, and TP53 was the most commonly altered gene.

Although these were larger scale studies than our study, to the best of our knowledge, our study is the first to use a custom- 
ized cfDNA NGS panel targeting the major HCC driver genes, incorporating molecular barcoding. Using an in-house customized panel targeting three HCC driver genes implemented on a robust and standardized NGS platform, we detected at least one pathogenic variant in plasma cfDNA among $68 \%$ of the patients analyzed (13/19). These included 16 variants of TP53 and nine variants of CTNNB1, and $13 \%$ of TP53 and $44 \%$ of CTNNB1 variants were located in reported hotspot regions. Of note, a possible reason that we did not detect the TERT promoter variant may be that it is more frequently seen in early-stage HCC [11], and this study did not include early-stage HCC patients. Importantly, all cfDNA variants identified in this study were present at very low frequencies, with median values of $0.17 \%$ and $0.07 \%$ for TP53 and CTNNB1 variants, respectively. This low frequency supports the use of a robust cfDNA NGS panel that incorporates molecular barcodes for achieving optimal sensitivity. Incorporation of molecular barcoding has significantly reduced false-positive errors associated with amplicon-based NGS methods and thereby allows for a sensitivity of variant detection down to $-0.001 \%$ [24]. We validated the detection limit of our customized cfDNA NGS panel using commercially available reference material.

We acknowledge some limitations of our study. First, somatic variant profiles from synchronously collected tumor biopsies were not available for concordant analysis. However, a previous study indicated that, even without prior knowledge of the variant repertoire in an HCC biopsy, high-depth sequence analysis of plasma cfDNA can represent somatic variants in an HCC biopsy in a significant proportion of therapy-naive HCC patients [25]. Second, as a pilot study, our study enrolled small number of patients. However, we found strong evidence that plasma cfDNA analysis using NGS can reliably detect pathogenic variants in $\mathrm{HCC}$ driver genes in HCC patients. Furthermore, as a proof-ofconcept study, correlations between detected cfDNA variants and clinical characteristics were not the main focus of this study. These should be assessed in a larger patient cohort in future studies. Lastly, we did not confirm the very-low-frequency variants using other methods, such as digital droplet PCR.

In conclusion, by using targeted cfDNA NGS, we achieved a very high coverage of the entire coding regions of three major HCC driver genes, allowing the detection of low-frequency variants in a large number of unique molecular families. cfDNA could be used as a reliable biomarker to identify somatic variants in HCC, and our results support the utility of CfDNA analysis in a larger cohort of HCC patients.

\section{ACKNOWLEDGEMENTS}

We thank all patients who participated in this study, the referring clinicians, and The Catholic Genetic Laboratory Center for assisting us with this study.

\section{AUTHOR CONTRIBUTIONS}

PSS, YK, MK, and SKY conceived and designed the work; HC, $A K$, and DK contributed to the acquisition of data; HJC wrote the manuscript; PSS, YK, MK, and SKY revised the manuscript critically for important intellectual content.

\section{CONFLICTS OF INTEREST}

No potential conflicts of interest relevant to this article were reported.

\section{RESEARCH FUNDING}

This research was partly supported by the Basic Science Research Program through the National Research Foundation of Korea (NRF) and funded by the Ministry of Science, ICT and Future Planning (2019R1I1A1A01059642, S.P.S).

\section{ORCID}

Hyojin Chae https://orcid.org/0000-0001-5870-1887

Pil Soo Sung https://orcid.org/0000-0002-5780-9607

Hayoung Choi

AhIm Kwon https://orcid.org/0000-0002-2348-0030

Dain Kang https://orcid.org/0000-0003-1555-2898

Yonggoo Kim Myungshin Kim

Seung Kew Yoon https://orcid.org/0000-0002-6496-8630 https://orcid.org/0000-0003-2808-3795 https://orcid.org/0000-0001-8632-0168 https://orcid.org/0000-0002-4476-4868

\section{REFERENCES}

1. Ferlay J, Soerjomataram I, Dikshit R, Eser S, Mathers C, Rebelo M, et al. Cancer incidence and mortality worldwide: sources, methods and major patterns in GLOBOCAN 2012. Int J Cancer 2015;136:E359-86.

2. Korean Liver Cancer Association and National Cancer Center. 2018 Korean Liver Cancer Association-National Cancer Center Korea practice guidelines for the management of hepatocellular carcinoma. Gut Liver 2019;13:227-99.

3. Farokhizadeh Z, Dehbidi S, Geramizadeh B, Yaghobi R, Malekhosseini $\mathrm{SA}$, Behmanesh M, et al. Association of microRNA polymorphisms with hepatocellular carcinoma in an Iranian population. Ann Lab Med 2019; 
39:58-66.

4. Yang JD. Detect or not to detect very early stage hepatocellular carcinoma? The western perspective. Clin Mol Hepatol 2019;25:335-43.

5. Yang K, Sung PS, You YK, Kim DG, Oh JS, Chun HJ, et al. Pathologic complete response to chemoembolization improves survival outcomes after curative surgery for hepatocellular carcinoma: predictive factors of response. HPB (Oxford) 2019;21:1718-26.

6. Sung PS, Yang H, Na GH, Hwang S, Kang D, Jang JW, et al. Long-term outcome of liver resection versus transplantation for hepatocellular carcinoma in a region where living donation is a main source. Ann Transplant 2017;22:276-84.

7. Li VD, Li KH, Li JT. TP53 mutations as potential prognostic markers for specific cancers: analysis of data from The Cancer Genome Atlas and the International Agency for Research on Cancer TP53 Database. J Cancer Res Clin Oncol 2019;145:625-36.

8. Khemlina G, Ikeda S, Kurzrock R. The biology of hepatocellular carcinoma: implications for genomic and immune therapies. Mol Cancer 2017; 16:149.

9. Huang Z, Hua D, Hu Y, Cheng Z, Zhou X, Xie Q, et al. Quantitation of plasma circulating DNA using quantitative PCR for the detection of hepatocellular carcinoma. Pathol Oncol Res 2012;18:271-6.

10. Yang YJ, Chen H, Huang P, Li CH, Dong ZH, Hou YL. Quantification of plasma hTERT DNA in hepatocellular carcinoma patients by quantitative fluorescent polymerase chain reaction. Clin Invest Med 2011; 34:E238.

11. Schulze K, Imbeaud S, Letouzé E, Alexandrov LB, Calderaro J, Rebouissou $S$, et al. Exome sequencing of hepatocellular carcinomas identifies new mutational signatures and potential therapeutic targets. Nat Genet 2015;47:505-11.

12. Totoki Y, Tatsuno K, Covington KR, Ueda H, Creighton CJ, Kato M, et al. Trans-ancestry mutational landscape of hepatocellular carcinoma genomes. Nat Genet 2014;46:1267-73.

13. Diehl F, Schmidt K, Choti MA, Romans K, Goodman S, Li M, et al. Circulating mutant DNA to assess tumor dynamics. Nat Med 2008;14: 985-90.

14. Ulrich BC and Paweletz CP. Cell-free DNA in oncology: gearing up for clinic. Ann Lab Med 2018;38:1-8.
15. Vollbrecht C, Lehmann A, Lenze D, Hummel M. Validation and comparison of two NGS assays for the detection of EGFR T790M resistance mutation in liquid biopsies of NSCLC patients. Oncotarget 2018;9: 18529-39.

16. Cancer Genome Atlas Research Network. Comprehensive and integrative genomic characterization of hepatocellular carcinoma. Cell 2017;169:1327-41.e23.

17. Fujimoto A, Furuta M, Totoki $Y$, Tsunoda $T$, Kato M, Shiraishi $Y$, et al. Whole-genome mutational landscape and characterization of noncoding and structural mutations in liver cancer. Nat Genet 2016;48:500-9.

18. Heimbach JK, Kulik LM, Finn RS, Sirlin CB, Abecassis MM, Roberts $L R$, et al. AASLD guidelines for the treatment of hepatocellular carcinoma. Hepatology 2018;67:358-80.

19. Jeong TD, Kim MH, Park S, Chung HS, Lee JW, Chang JH, et al. Effects of pre-analytical variables on cell-free DNA extraction for liquid biopsy. Lab Med Online 2019;9:45-56.

20. He HJ, Stein EV, Konigshofer Y, Forbes T, Tomson FL, Garlick R, et al. Multilaboratory assessment of a new reference material for quality assurance of cell-free tumor DNA measurements. J Mol Diagn 2019; 21:658-76.

21. Rebouissou S, Franconi A, Calderaro J, Letouzé E, Imbeaud S, Pilati C et al. Genotype-phenotype correlation of CTNNB1 mutations reveals different $\beta$-catenin activity associated with liver tumor progression. Hepatology 2016;64:2047-61.

22. Kaseb AO, Sánchez NS, Sen S, Kelley RK, Tan B, Bocobo AG, et al. Molecular profiling of hepatocellular carcinoma using circulating cellfree DNA. Clin Cancer Res 2019;25:6107-18.

23. Howell J, Atkinson SR, Pinato DJ, Knapp S, Ward C, Minisini R, et al. Identification of mutations in circulating cell-free tumour DNA as a biomarker in hepatocellular carcinoma. Eur J Cancer 2019;116:56-66.

24. Schmitt MW, Kennedy SR, Salk JJ, Fox EJ, Hiatt JB, Loeb LA. Detection of ultra-rare mutations by next-generation sequencing. Proc Natl Acad Sci U S A 2012;109:14508-13.

25. Ng CKY, Di Costanzo GG, Tosti N, Paradiso V, Coto-Llerena M, Roscigno $G$, et al. Genetic profiling using plasma-derived cell-free DNA in therapy-naive hepatocellular carcinoma patients: a pilot study. Ann Oncol 2018;29:1286-91. 